\title{
Labyrinthe
}

$7 \mid 2000$

Numéro 7

\section{La politique de légitimation symbolique de l'Union européenne}

\section{François Forêt}

\section{(2) OpenEdition \\ Journals}

Édition électronique

URL : http://journals.openedition.org/labyrinthe/735

DOI : $10.4000 /$ labyrinthe.735

ISSN : 1950-6031

Éditeur

Hermann

\section{Édition imprimée}

Date de publication : 30 octobre 2000

Pagination : 161-163

\section{Référence électronique}

François Forêt, "La politique de légitimation symbolique de l'Union européenne », Labyrinthe [En ligne], 7 | 2000, mis en ligne le 20 avril 2005, consulté le 06 mai 2019. URL : http://journals.openedition.org/ labyrinthe/735; DOI : 10.4000/labyrinthe.735

Ce document a été généré automatiquement le 6 mai 2019.

Propriété intellectuelle 


\title{
La politique de légitimation symbolique de l'Union européenne
}

\author{
François Forêt
}

Depuis les déboires électoraux de la ratification du Traité de Maastricht, la dénonciation $\mathrm{du}$ « déficit démocratique » de l'Union européenne se heurte au constat des limites de la construction juridique d'une citoyenneté communautaire par en haut, et à la faiblesse des mobilisations d'en bas. S'ensuit un entrecroisement complexe de discours parfois intrinsèquement contradictoires : à l'affirmation volontariste d'une identité européenne, réquisitionnant Charlemagne ou misant sur l'euro, répond la proclamation du caractère irréductible des nations*.

2 De ce débat émerge néanmoins une constante : le prisme stato-national reste très prégnant, que l'on refuse de penser la souveraineté politique dans un autre cadre ou que l'on s'efforce d'imaginer une nouvelle manière d'être en politique. Les moyens mis en œuvre pour développer le sentiment d'appartenance communautaire s'inspirent plus ou moins explicitement du modèle canonique de l'État-Nation, lors même que les finalités poursuivies et les conditions du travail identitaire ont considérablement changé.

3 La question est alors de déterminer dans quelle mesure la matrice ayant produit les "communautés imaginées " nationales structure encore les schèmes de pensée et d'action. Le moule peut-il être adapté aux nouvelles exigences de l'intégration européenne, est-il totalement obsolète ou le problème se joue-t-il ailleurs ? La réflexion porte plus spécifiquement sur la capacité d'un pouvoir, dans les circonstances actuelles, à mener une entreprise de construction symbolique par laquelle il se donne à voir comme la force légitime d'organisation du social et l'incarnation de l'identité collective, et s'inscrit dans l'espace et le temps.

4 Les conditions de production symbolique à l'échelle de l'Union européenne se révèlent totalement inédites. Sur les trois plans fondamentaux de l'identité (pouvoir, espace, temps), le processus communautaire remet en cause les principes structurants de l'ÉtatNation en la matière.

Le symbole émane d'un centre. Il renvoie à une institution habilitée à édicter et à imposer le code qui donne sens à son usage. L'État avait établi le partage d'une langue ${ }^{2}$, d'un 
drapeau, etc. Le système politico-bureaucratique communautaire, polycentrique et polyculturel, ne permet à aucun acteur de se poser en locuteur légitime unique et universel.

6 Le symbole postule un territoire. Il requiert, pour être efficace, la définition d'un périmètre où ses codes seront maîtrisés et reconnus prioritairement à tous les autres. La sphère de souveraineté d'un État se confond avec l'espace homogène d'intelligibilité et d'efficacité de ses signes officiels. La spatialité communautaire, elle, demeure fragmentée, et ses frontières sujettes à des révisions permanentes au fil des élargissements successifs. L'inexistence d'une force jouissant du monopole de la violence physique et symbolique légitime et l'exerçant d'une manière uniforme dans des limites données interdit de parler d'une territorialité européenne.

7 Le symbole procède d'une temporalité. Produit d'une histoire, il ne prend sens qu'en étant replacé dans une lignée de signes et en étant périodiquement réactualisé. L'État régulait le temps collectif en organisant la mémoire par la commémoration et l'enseignement. Il assurait la triple fonction de mise en forme du passé, de marquage du présent par l'organisation de grands événements, et d'encadrement de l'avenir par la restriction des sens sociaux possibles. La mise sur agenda de l'action publique communautaire favorise certes la coordination des rythmes politiques des États membres, mais les quinze histoires nationales ne se fondent pas dans une chronologie unique et la perception de l'actualité demeure tributaire d'autant de conjonctures particulières.

8 Comment dès lors les institutions de l'Union européenne peuvent-elles produire du symbolique, et les contraintes avec lesquelles elles doivent composer sont-elles compatibles avec les objectifs qu'elles s'assignent ou qui leur sont assignés ? Pour répondre à cette double interrogation, trois terrains d'analyse ont été retenus.

9 Les brochures grand public émises par la Commission à plusieurs centaines de milliers d'exemplaires constituent un discours par lequel l'UE se donne à voir aux citoyens tant dans la diversité de ses politiques sectorielles (agriculture, développement territorial, etc.) que dans sa globalité, comme système institutionnel ou comme résultante d'un processus historique enclenché avec la déclaration Schuman du 9 mai 1950.

10 L'accueil de près de trois cent mille visiteurs (jeunes ou leaders d'opinion) par an est l'occasion pour le Parlement de se mettre en scène dans ses propres murs. Dans cette confrontation directe entre le citoyen, son représentant et l'institution, se négocient les modalités de l'articulation de trois niveaux territoriaux (local-national-communautaire) et la capacité pour l'assemblée de se faire reconnaître comme un «centre » où se fait l'Europe en suscitant un effet " hic et nunc ».

11 La réunion semestrielle du Conseil européen constitue, de par la qualité des participants, l'intensité de la couverture médiatique qui en résulte et la portée des orientations qui y sont arrêtées, un événement majeur de la vie politique communautaire. Les sommets scandent les grands rythmes de l'intégration et marquent son histoire en donnant leurs noms aux traités. Se tenant à chaque fois dans une ville différente, ils esquissent par ailleurs une cartographie cérémonielle de l'Union. L'analyse du protocole et de la relation faite par les presses des États membres de ces rencontres éclaire le sens de cette manifestation rituelle vieille d'un quart de siècle.

12 À la lumière des premiers résultats de notre travail, l'État-Nation demeure l'entité politique de référence. Il oppose la force d'inertie de ses représentations fondatrices aux velléités de changement, et impose son modèle et ses catégories de pensée et d'action 
même à ceux qui prétendent le remettre en cause. Sous l'emprise de cette double contrainte, l'Union européenne peine à se faire reconnaître comme producteur symbolique légitime. Un registre communautaire autonome est certes en voie de constitution à travers les interactions toujours plus nombreuses entre les acteurs institutionnels. Mais la question de sa diffusion des élites vers les masses reste posée.

\section{NOTES}

*. Cette réflexion s'inscrit dans le cadre de la préparation d'un doctorat de Science politique à l'Université Paris I Panthéon-Sorbonne, sous la direction du Professeur Philippe Braud.

1. Anderson B., L'Imaginaire national. Réflexions sur l'origine et l'essor du nationalisme, Paris, La Découverte, 1996 (traduction de Imagined Communities, London, Verso, 1983).

2. Ou la normalisation d'un plurilinguisme limité. 